\title{
A UCD approach towards the design, development and assessment of accessible applications in a large scale European Integrated project
}

\author{
Karel Van Isacker ${ }^{1}$, Karin Slegers ${ }^{2}$, Maria Gemou ${ }^{3}$, Evangelos Bekiaris ${ }^{4}$ \\ ${ }^{1}$ European Platform for Rehabilitation, 15, rue de Spa, B-1000 Brussels, Belgium \\ aegis@epr.eu \\ ${ }^{2}$ Centre for User Experience Research (CUO), IBBT / K.U.Leuven, Parkstraat 45 Bus 3605 \\ - 3000 Leuven - Belgium \\ karin.slegers@soc.kuleuven.be \\ ${ }^{3,4}$ Centre for Research and Technology Hellas Hellenic Institute of Transport, 17, Posidonos \\ Av., 17455 Alimos, Greece \\ \{mgemou, abek\}@certh.gr
}

\begin{abstract}
EGIS (Open Accessibility Everywhere: Groundwork, Infrastructure, Standards) is a user-centred project, involving several user groups (users with visual, hearing, motion, speech and cognitive impairments as well as application developers) throughout the design, development and assessment phases. In this paper the holistic UCD (User Centred Design) approach of the project is introduced. This approach ensures that the project's objectives to determine whether $3^{\text {rd }}$ generation access techniques will provide a more accessible, more exploitable and deeply embeddable approach in mainstream ICT applications (desktop, rich Internet and mobile applications) are met, with the full support and involvement of a huge end-user group in every single step of the design, development and deployment of accessible mainstream ICT.
\end{abstract}

Keywords: accessible, mainstream ICT, Open Accessibility Framework, Holistic User Centred Design, design, development, assessment, end-user groups, desktop, rich web applications, Java-based mobile devices.

\section{Introduction}

Implementing a pan-European project, involving a wide plethora of stakeholders, and addressing one of the biggest needs for people with disabilities, namely affordable assistive technologies, would be an empty box, were it not for the in-depth involvement of these very end-users in every step of the project: its design, development and assessment. Following a holistic UCD (User Centred Design) approach, ÆGIS (Open Accessibility Everywhere: Groundwork, Infrastructure, Standards - http://www.aegis-project.eu/) aims to ensure that the user needs and interaction models for several user groups (users with visual, hearing, motion, speech and cognitive impairments as well as application developers) are identified and are considered throughout the entire project design, iterative development and assessment 
cycles. Based upon this approach, open source-based generalised accessibility support is developed into mainstream ICT devices/applications (desktop, rich web applications, and Java-based mobile devices), fully abiding to the needs of the enduser groups. All developments will be iteratively tested with hundreds of end users, developers and experts in 3 phases and 4 pilot sites across Europe (Belgium, Spain, Sweden and the UK).

\section{Methodology}

The User Centred Design approach for ÆGIS is planned in four phases. The first phase aims at gathering the needs for all user groups: end users with disabilities, and assistive technology experts. In the second phase the insights in the user needs will be translated into user requirements which will be the basis for the conceptual models that will be made in Phase three. In this phase, the model will be gradually and iteratively built into prototypes of increasing fidelity in a co-design approach. The result of the third phase, the working prototypes, will in the final and fourth phase be tested in the field.

\subsection{Phase 1}

To understand the users and to identify user needs, thorough analyses of the users, their tasks and their contexts will be done. A combination of quantitative and qualitative methods will be used to gather deep and rich insights on the one hand and to gather data of a substantial panel of users.

On a quantitative level, the user, task and context analysis will be performed by means of interviews that will be conducted by phone. For this purpose, separate questionnaires are made for end users with disabilities and for experts. In addition, different questionnaires are constructed for the ÆGIS application areas (desktop applications, mobile phone applications and rich internet applications).

On a qualitative level, a subset of the questionnaire participants will be interviewed face to face, allowing the discussion of relevant topics on a deeper level and doing contextual inquiries to observe the users while doing relevant tasks.

\subsection{Phase 2}

Aiming at translating the insights and user needs gathered in Phase 1 into user requirements, a number of User Centred Design techniques will be deployed. The main purpose of this phase is to set up the user requirements for AEGIS in a format usable for the remainder of the project. To achieve this, personas ${ }^{1}$, use cases to be translated in UML diagrams, user scenarios and a list of user requirements will be

\footnotetext{
${ }^{1}$ Personas are summaries of some typical real-user characteristics (i.e. age, family situations, motivations, behavior, personal experiences and end goals), collected during the user-andtask analysis of the end-users.
} 
created. To verify the relevance and accuracy of these formats, focus group meetings with end users and experts will be organised.

\subsection{Phase 3}

Starting from the personas, use cases, user scenarios and list of user requirements constructed in the previous phase, conceptual models of the assistive technologies, applications and developers' tools will be made. These models will present the high level functionalities and user interaction.

In the ÆGIS project, from the early beginning, a co-design (or participatory design) approach will be followed. In this respect, ÆGIS researchers, developers and designers will team up with target user representatives (both end users and experts). This team will follow an iterative process of designing, developing and iterating prototypes of increasing fidelity. Based on the created conceptual models, mock-ups of the intended applications will be co-designed. These mock-ups will be evaluated with end users on their usefulness, usability, and the user acceptance via qualitative techniques such as co-discovery, thinking aloud protocol, cognitive walkthrough, expert evaluations, etc. The feedback gathered on the mock-ups will be used for their optimisation on specifications and design level and the implementation of prototypes of progressively increasing fidelity, with regard to user requirements.

The process of co-design and evaluation is to be iteratively repeated until hifi, working prototypes are available. These working prototypes will then be extensively tested in the usability laboratories, allowing, in this case, the measurement of both objective measures - performance, eye tracking, psycho-physiological measures - and subjective measures - user experience, perceived usefulness, etc.

\subsection{Phase 4}

When working prototypes are available that are suitable for testing outside of the lab, extended field trials will be organised. In these field trials, end users will test the prototypes for a certain amount of time in their own contexts, for their own tasks. During the field trials, information about the user experience, usability issues, etc. will be collected by using diaries and by doing contextual inquiries. Both before and after the trial period, performance tests will be done to be able to assess whether the prototypes have improved end users' task performance. In addition to the automatic logging of the users' tasks performance, interviews through several types of questionnaires will be planned to collect extensive feedback on the final prototypes.

\section{In Practice}

This integrated and holistic UCD model will now be applied in three distinct evaluation iterations: (a) Initial concept testing (using simulation and storyboarding) with end users and other related stakeholders (UCD phase 2); (b) Creation of tentative 
content and user interfaces for initial baseline testing; and (c) Full testing and trialling of the demonstrators and applications by end users and experts (UCD phase 3 and 4). The UCD methodology was structured across all project phases to follow the modelled needs of people with disabilities, elderly and developers and the user interaction elements in using rich applications of mainstream ICT. The UCD methodology used for eliciting AT/AAC features and functionality within ÆGIS is heuristics-based, and will ensure that the different stakeholders are able to express their own priorities both with regard to which prototypes/products they would most like to see developed but also within that what these products should be capable of doing for them. More specifically, 3 specific phases can be identified: the design, development and assessment phase. Design (UCD phase 2): Defining some essential functionality and feel for each prototype on each platform. Development: Initial concept testing with users (using simulation or storyboarding to "set the scene") and creating some tentative content \& user interfaces for initial user testing (UCD phase 3). Assessment: Testing \& trialling the prototype demonstrators at recognised AT end user Centres (UCD phase 3 and 4).

\subsection{Design}

To apply UCD, a thorough understanding is needed of the targeted end-users. In the context of the project, following end-users were identified:

\begin{tabular}{|c|c|c|c|c|c|c|}
\hline User Groups & $\begin{array}{l}\text { Subgroups } \\
\text { (1) }\end{array}$ & Limitations & $\begin{array}{c}\text { Sub-groups } \\
(2)\end{array}$ & Sub-groups (3) & Effects on activity & ICF code \\
\hline \multirow[t]{5}{*}{$\begin{array}{l}\text { People with } \\
\text { disabilities } \\
\text { \& elderly }\end{array}$} & \multirow[t]{4}{*}{$\begin{array}{l}\text { 1. Blind and } \\
\text { low-vision } \\
\text { users }\end{array}$} & \multirow[t]{4}{*}{$\begin{array}{l}\text { Vision limitations or } \\
\text { other visual } \\
\text { limitations }\end{array}$} & \multirow[t]{3}{*}{$\begin{array}{l}\text { 1.a Partly } \\
\text { sighted }\end{array}$} & $\begin{array}{l}\text { 1.a1 Slight or } \\
\text { moderate } \\
\text { limitations } \\
\text { (visual acuity, } \\
\text { slow } \\
\text { accommodation, } \\
\text { etc) }\end{array}$ & $\begin{array}{l}\text { Difficulties in reading } \\
\text { (font size, contrast), } \\
\text { identifying images. }\end{array}$ & \multirow[t]{4}{*}{$\begin{array}{l}\text { b2100, } \\
\text { b2101, } \\
\text { b21020, } \\
\text { b21021, } \\
\text { b21022, } \\
\text { b21023 }\end{array}$} \\
\hline & & & & $\begin{array}{l}\text { 1.a2 Limited } \\
\text { sight angle }\end{array}$ & $\begin{array}{l}\text { Reduction of the } \\
\text { peripheral vision (upper } \\
\text { and lower) }\end{array}$ & \\
\hline & & & & $\begin{array}{l}\text { 1.a3 Limited } \\
\text { color vision }\end{array}$ & $\begin{array}{l}\text { Difficulties in the colour } \\
\text { perception }\end{array}$ & \\
\hline & & & \multicolumn{2}{|l|}{ 1.b Fully blind } & $\begin{array}{l}\text { Communicating with - } \\
\text { receiving - non-verbal } \\
\text { messages (gestures, } \\
\text { symbols and drawings). } \\
\text { Use of screen readers } \\
\text { and other assistive } \\
\text { technologies. }\end{array}$ & \\
\hline & $\begin{array}{l}\text { 2. Motor } \\
\text { impairment } \\
\text { users (Upper } \\
\text { limbs) }\end{array}$ & $\begin{array}{l}\text { Limitations in } \\
\text { motion or strength } \\
\text { or coordination or } \\
\text { anthropometric } \\
\text { limitations of upper } \\
\text { limbs. Includes } \\
\text { tetraplegic, } \\
\text { hemiplegic, one- } \\
\text { handed user, co- } \\
\text { ordination and } \\
\text { balance disorders, }\end{array}$ & \multicolumn{2}{|c|}{$\begin{array}{l}\text { 2.a Dexterity difficulties or slight } \\
\text { restriction on arms or hands }\end{array}$} & $\begin{array}{l}\text { Difficulty in pressing } \\
\text { keys, or requirements } \\
\text { of accuracy in } \\
\text { interacting with } \\
\text { interfaces (screen, } \\
\text { mouse, etc). }\end{array}$ & $\begin{array}{l}\text { b750, } \\
\text { b755, } \\
\text { b760, } \\
\text { b765, } \\
\text { b780 }\end{array}$ \\
\hline
\end{tabular}




\begin{tabular}{|c|c|c|c|c|c|c|}
\hline User Groups & $\begin{array}{c}\text { Subgroups } \\
\text { (1) }\end{array}$ & Limitations & $\begin{array}{c}\text { Sub-groups } \\
(2)\end{array}$ & Sub-groups (3) & Effects on activity & ICF code \\
\hline & & $\begin{array}{l}\text { and varying } \\
\text { degrees of } \\
\text { neuromuscular } \\
\text { impediment }\end{array}$ & \multicolumn{2}{|c|}{$\begin{array}{l}\text { 2.b Moderate restriction on hand } \\
\text { use }\end{array}$} & $\begin{array}{l}\text { Difficulty in pressing } \\
\text { keys, or requirements } \\
\text { of accuracy in } \\
\text { interacting with } \\
\text { interfaces (screen, } \\
\text { mouse, etc). }\end{array}$ & \\
\hline & & & \multicolumn{2}{|c|}{$\begin{array}{l}\text { 2.c Severe or complete restriction } \\
\text { on hand use }\end{array}$} & $\begin{array}{l}\text { Difficulty or } \\
\text { impossibility in pressing } \\
\text { keys, or requirements } \\
\text { of accuracy in } \\
\text { interacting with } \\
\text { interfaces (screen, } \\
\text { mouse, etc). Needs of } \\
\text { alternative ways of } \\
\text { interaction: speech } \\
\text { recognition, eyes, head } \\
\text { mouse, etc }\end{array}$ & \\
\hline & $\begin{array}{l}\text { 3. Cognitive } \\
\text { impairment } \\
\text { users / } \\
\text { learning } \\
\text { difficulties }\end{array}$ & $\begin{array}{l}\text { Cognitive } \\
\text { limitations in } \\
\text { operating and } \\
\text { performing tasks, } \\
\text { learning, } \\
\text { comprehension, } \\
\text { adaptive behaviour } \\
\text { and social skills. } \\
\text { Includes Down } \\
\text { Syndrome, Autism, } \\
\text { Cerebral Palsy, } \\
\text { Brain Injury and } \\
\text { Alzheimer }\end{array}$ & \multicolumn{2}{|c|}{$\begin{array}{l}\text { 3.a Slight cognitive limitation and } \\
\text { low support need }\end{array}$} & $\begin{array}{l}\text { Limitations in } \\
\text { information processing, } \\
\text { tasks organization, } \\
\text { development, operating } \\
\text { new technologies, } \\
\text { moving on complex } \\
\text { environments, } \\
\text { limitations in short- } \\
\text { term-memory, } \\
\text { concentrating, learning, } \\
\text { difficulties in use of } \\
\text { language, recognition of } \\
\text { signs and symbol }\end{array}$ & $\begin{array}{l}\text { b117, } \\
\text { b122, } \\
\text { b140, } \\
\text { b144, } \\
\text { b160, } \\
\text { b164, } \\
\text { b172 }\end{array}$ \\
\hline & & & \multicolumn{2}{|c|}{$\begin{array}{l}\text { 3.b Moderate and severe cognitive } \\
\text { limitation and medium and high } \\
\text { support need }\end{array}$} & $\begin{array}{l}\text { Limitations in } \\
\text { information processing, } \\
\text { tasks organization, } \\
\text { development, operating } \\
\text { new technologies, } \\
\text { moving on complex } \\
\text { environments, } \\
\text { limitations in short- } \\
\text { term-memory, } \\
\text { concentrating, learning, } \\
\text { difficulties in use of } \\
\text { language, recognition of } \\
\text { signs and symbol }\end{array}$ & \\
\hline & $\begin{array}{l}\text { 4. Hearing } \\
\text { impairment } \\
\text { users }\end{array}$ & $\begin{array}{l}\text { Hearing limitations } \\
\text { or other audio } \\
\text { limitations }\end{array}$ & \multicolumn{2}{|c|}{ 4.a Slight or moderate limitation } & $\begin{array}{l}\text { Difficulties in hearing } \\
\text { vocal information, } \\
\text { audible signs, warning } \\
\text { messages, etc }\end{array}$ & b230 \\
\hline & & & \multicolumn{2}{|c|}{$\begin{array}{l}\text { 4. b Severe limitation or total } \\
\text { deafness }\end{array}$} & $\begin{array}{l}\text { No hearing vocal } \\
\text { information, audible } \\
\text { signs, warning } \\
\text { messages, and } \\
\text { sometimes in } \\
\text { understanding verbal } \\
\text { language }\end{array}$ & \\
\hline & $\begin{array}{l}\text { 5. Speech / } \\
\text { Communicatio } \\
\text { n impairment } \\
\text { users }\end{array}$ & $\begin{array}{l}\text { Limitations in } \\
\text { speaking and } \\
\text { conversation and } \\
\text { sometimes in } \\
\text { understanding } \\
\text { verbal language }\end{array}$ & $\begin{array}{l}\text { 5.a Aphasia, } \\
\text { loss of the } \\
\text { ability to } \\
\text { produce } \\
\text { and/or } \\
\text { comprehend } \\
\text { language }\end{array}$ & $\begin{array}{l}\text { 5.al Slight and } \\
\text { moderate } \\
\text { comprehension } \\
\text { and/or } \\
\text { production } \\
\text { difficulties }\end{array}$ & $\begin{array}{l}\text { Difficulties in } \\
\text { comprehension } \\
\text { (simplified language, } \\
\text { may need } \\
\text { symbol/spoken support) } \\
\text { and/or in production } \\
\text { (simple cues to aid } \\
\text { listeners and systems to } \\
\text { assist communication) }\end{array}$ & b167 \\
\hline
\end{tabular}




\begin{tabular}{|c|c|c|c|c|c|c|}
\hline User Groups & $\begin{array}{c}\text { Subgroups } \\
\text { (1) }\end{array}$ & Limitations & $\begin{array}{c}\text { Sub-groups } \\
(2)\end{array}$ & Sub-groups (3) & Effects on activity & ICF code \\
\hline & & & & $\begin{array}{l}\text { 5.a2 Severe and } \\
\text { complete } \\
\text { comprehension } \\
\text { and/or } \\
\text { production } \\
\text { difficulties }\end{array}$ & $\begin{array}{l}\text { Difficulties in } \\
\text { comprehension } \\
\text { (Symbolic commu- } \\
\text { nication and alternative } \\
\text { methods) and/or in } \\
\text { production (Alternative } \\
\text { artificial speech } \\
\text { alternatives) }\end{array}$ & \\
\hline & & & \multirow{2}{*}{$\begin{array}{l}\text { 5.b Stuttering } \\
\text { \& Dysarthria - } \\
\text { motor speech } \\
\text { disorder } \\
\text { resulting from } \\
\text { neurological } \\
\text { injury, } \\
\text { characterised } \\
\text { by poor } \\
\text { articulation. }\end{array}$} & $\begin{array}{l}\text { 5.b1 Slight and } \\
\text { moderate }\end{array}$ & $\begin{array}{l}\text { Slight and moderate } \\
\text { difficulties in } \\
\text { articulation. Use of } \\
\text { augmentative systems } \\
\text { and simple cues to aid } \\
\text { listeners }\end{array}$ & \multirow[t]{2}{*}{$\begin{array}{l}\text { b310, } \\
\text { b320, } \\
\text { b330 }\end{array}$} \\
\hline & & & & $\begin{array}{l}\text { 5.b2 Severe and } \\
\text { complete }\end{array}$ & $\begin{array}{l}\text { Severe and complete } \\
\text { difficulties in } \\
\text { articulation. Use of } \\
\text { artificial speech } \\
\text { alternatives (only a few } \\
\text { words discernible or } \\
\text { cannot articulate) }\end{array}$ & \\
\hline \multirow[t]{7}{*}{ Developers } & \multicolumn{6}{|c|}{ 6. AT developers/experts } \\
\hline & \multicolumn{6}{|c|}{ 7. Mainstream software developers/experts } \\
\hline & \multicolumn{6}{|c|}{ 8. OS developers } \\
\hline & \multicolumn{6}{|c|}{ 9. Web application developers } \\
\hline & \multicolumn{6}{|c|}{ 10. Desktop developers } \\
\hline & \multicolumn{6}{|c|}{ 11. Mobile application developers } \\
\hline & \multicolumn{6}{|c|}{ 12. Accessibility assessors } \\
\hline
\end{tabular}

Fig. 1. Identified end-users categories.

The above analysis of the target groups was important since it guided the field studies with more than 160 end-users and experts which were undertaken via questionnaires and interviews in Sweden, UK, Belgium and Spain. The questionnaires were specifically adjusted to the targeted end-user, whether s/he was a person with a disability, or an expert user (expert, tutor, developer). During this phase, valid information about the context of use of ICT-based products and services was collected. The collected data provided the basis for prioritising user requirements for system and accessibility -oriented innovations.

The questionnaires and interviews covered various types of ICT applications, and identified misallocation of functions between users and existing mainstream technology (i.e. identify cases where a human skill is not used properly), and elucidated the different viewpoints and individuality among the current user base of ICT.

In order to bridge the outcomes of these field studies with the next stage of the ÆGIS user-centred approach, namely the creation of alternative accessibility solutions, user requirements were specified and modelled. A method to make information from user research more appropriate for use by designers is the design of personas [1]. This involves the creation of fictitious characters, built on user research data, which represent the most important user groups. The benefit of using specific characters is that they give the designers a more concrete item to work with. A concrete person is easier to focus on than user profiles or just all information about the users. The purpose of creating the persona is to get insight into the users and create empathy for them. It is also ideal for communicating this to all stakeholders in 
the organisations involved in creating a new application. It assures that everyone always has a reference to the same user.

To make these personas more concrete user scenarios [2] will be defined. Such scenarios are stories about a persona or more personas and their activities. It emphasises the goals users wants to reach with a specific product. Next to this, a scenario also describes the persons' expectations concerning a particular system, the most critical task(s) that s/he wants to execute, which task s/he executes frequently, etc. Each scenario will contain at least one actor and one goal. Within this task, it is also important to integrate the users' requirements model with the corresponding stakeholders' requirements model and combine them into one integrated model.

Based on the personas, user scenarios and user requirements, one or more conceptual model(s) are developed. A conceptual model is a translation of a number of integrated ideas and concepts about how a system should look like and what its functionalities should be for the end-user. In other words, it specifies the specific design of a prototype based on the user and task analysis. In order to be able to develop a suitable (and useful) conceptual model, one needs to look at the icons and metaphors to use and at the mental models (which attempts to describe the structure of the mental representations that people use for everyday reasoning and problem solving) of the application that the users have built. This type of model is not supposed to be very detailed, but in the end the basic principles of the product must be present and clear.

The collected data are then transformed into distinct use cases [3] and application scenarios with reference to the different applications, environments and contexts (desktop accessibility, web application accessibility, cell phone and PDA accessibility). This involves the previously identified user groups. Based on the conceptual models, the corresponding use cases will be built, translating the model into a "description of sequences of events that, taken together, lead to a system doing something useful” [4]. Developing use cases is a joint task between users, usability engineers and software engineers. Therefore use cases should be understandable to end users and correspond with their idea of the application, while being concrete and task-oriented enough for software engineers to technically design and implement the application. Thus they will be iteratively evaluated by end-users via e.g. user workshops and dedicated user focus groups that will take place in each of the pilot testing sites (Sweden, UK, Belgium, Spain). These local national workshops aim at a better understanding of the user and organisational requirements, and at discussing and agreeing the details of the intended context of use. Participants range from end users and their respective national representative organisations to product providers, managers, developers, marketing specialists, and evaluation specialists). These workshops will be used to validate the draft use cases and application scenarios.

After the needed fine-tuning the use cases will be finalised and captured into Unified Modelling Language (UML), for uptake by the developing workpackages. As proven successful already in previous projects (such as ASK-IT - IST-2003-511298, OASIS - IST-2007-215754), a methodology will be applied that provides a use cases model which is comprised of use cases descriptions and use cases diagrams. The description will contain actors/users, scope, preconditions, stakeholders elements, and the specific user scenarios in ÆGIS. For each use case a use case diagram will be designed, to graphically represent them, using UML. Subsequently, a pan-European 
workshop, gathering stakeholders and end-user groups is organised to review the use cases and scenarios, and gather feedback in order to adjust and finalise them.

\subsection{Development}

To achieve an on-going and practicable dialogue with the system developers during the embryonic development process, the project will work closely with a few experienced end users of AT/AAC products and their support teams. While they are small in number and pre-selected according to specific disability and level of AT experience (in order to be more effective contributors to the field work), they represent a good cross-section of the client group.

UCD in the context of AT/AAC prototype development places the end user, user organisations and support teams at the fulcrum of the design and testing process. This is essential for a genuinely iterative approach to AT/AAC design and will be strictly followed within ÆGIS.

Work starts by gathering the commitment of all concerned in the development process to the user-centred design philosophy, and to achieve consensus on the plan whereby there is ample time and opportunity for engaging in user requirements elicitation and testing as well as more technical aspects of development. Consensus needs to be gained also among the design and development teams (a) that active user involvement in the project is not simply at the end, (b) that user involvement in this project is a particularly challenging priority due to the extremely diverse nature of the target user audience and the inclusion goal, and (c) that everything users see, hear and touch shall be designed together, by a multidisciplinary team.

A UCD Implementation Plan will be the outcome, specifying how much iteration will be carried out and timelines for each, as well as when each method should be used, taking into account the budget, timescales, resources, skills and other constrains. A range of UCD principles and tried and tested interview tools will be included in the UCD Implementation Plan, drawing experience from previous UCD projects, such as PCAD (TIDE Project No. 3211 DE), WWAAC (IST-2000- 27518), and most recently COGAIN (IST-2003-5115). This Plan shall be a working document, which is first produced in outline terms and which is then reviewed, maintained, extended and updated during the design, development and assessment process.

First low-end prototypes (or mock-ups of the system) are considered as being good enough to evaluate the overall structure of the interface of the application and the products user-friendliness. Experts or end-users work (walk) through scenarios on the system while a facilitator shuffles the screens. The usability of such prototypes can be investigated with expert evaluations, user tests or a combination of both methods. During the expert test and user evaluation real usability problems will be investigated and listed up, ordered by priority and will be recommended to fix those problems.

\subsection{Assessment}

The project will ensure that representatives from all impaired end users as well as developers open source communities are actively and centrally engaged in ÆGIS’ 
mission statement to provide "accessibility (that is) open, plug and play, personalised and configurable”, including a focus on young, socially excluded impaired users and their hinterland of AT infrastructural support (facilitators, families, AT professionals and AT developers), as well as elderly and people who are not familiar with technology.

Relevant end-user partners will be vigilant through the various project phases, leading to the demonstration of applications and devices, so as "to be true to what they are" from an end user perspective. The accessible mainstream consumer products (desktop environment, web applications, new access tools, and mobile devices) will be thoroughly tested by strong cohorts of end users (over 160), experts (over 80) and developers (over 20) in the 4 sites across Europe. They will be engaged through focus groups, questionnaires, interviews and workshops, and actual testing to ensure that the promise of a "seamless integration of personalised assistive solutions for ICT access" is clearly met, fully matching the end-users' needs.

\section{Conclusion}

The UCD methodology and practical implementation as presented in the previous, heralds the full involvement of end-users in the ÆGIS project, thus ensures a fully user driven approach. The resulting project outcomes should as such accommodate at the highest extent the needs of end-users (persons with various disabilities and developers), and should set the path for further in-depth user involvement for any other projects that aim at having the end-user at the core of their development.

\section{References}

1. Pruitt, J., \& Adlin, T. (2006). The persona lifecycle - Keeping people in mind throughout product design. San Fransisco: Morgan Kaufmann Publishers.

2. Rosson, M.B., \& Carroll, J.M. (2002). Usability engineering - scenario-based development of human-computer interaction. San Fransisco: Morgan Kaufmann Publishers.

3. Overgaard, G., \& Palmkvist, K. (2005). Use cases - patterns and blueprints. Addison Wesley Publishers

4. Bittner, K., \& Spence, I (2002). Use Case Modelling. Addison Wesley Professional, 2-3. ISBN 0-201-70913-9.

5. Annex I "Description of Work", “Open Accessibility Everywhere: Groundwork, Infrastructure, Standards” (ÆGIS), 7th FW, ICT-2007.7.1, ICT \& Ageing, September 11, 2008. 